\title{
Effect of Natural Vestibular Stimulation on Self-Esteem Levels in Relation to Stress
}

\author{
Kumar SS ${ }^{*}$, Archana $\mathrm{R}^{2}$ and Mukkadan $\mathrm{JK}^{3}$ \\ ${ }^{1}$ Assistant Professor \& HOD (I/C), Department of Physiology, Vishnu Dental College, \\ India \\ 2Professor, Department of Physiology, Saveetha Medical College, Saveetha University, \\ India
}

${ }^{3}$ Research Director, Little Flower Medical Research Center, India

\section{Research article \\ Volume 3 Issue 3}

Received Date: July 05, 2018

Published Date: July 19, 2018

*Corresponding author: Dr. Sai Sailesh Kumar G, Assistant Professor \& HOD (I/C), Department of Physiology, Vishnu Dental College, Vishnupur, Bhimavaram, West Godavari District, Andhra Pradesh 534202, India, Email: dr.saisailesh@gmail.com

\section{Abstract}

The present study was designed to evaluate the effect of vestibular stimulation on self-esteem in young adults. The present study was conducted at Little Flower Institute of Medical Sciences and Research and Little Flower Medical Research Centre, Angamaly. 240 (120 males and 120 females) participants satisfying both inclusion and exclusion criteria were included in the study. This was a longitudinal follow-up study in which, participants were assessed three times. Selfesteem was assessed by using Rosenberg self-esteem scale. In the present study, it was observed that there was a significant increase in the self-esteem scores following the vestibular stimulation. The study supports adoption of vestibular stimulation as an adjunctive therapy to improve self-esteem. We recommend further detailed studies in this area. The current study provides convincing evidence for the beneficial effects of vestibular stimulation on self-esteem in relation to pre-examination stress among young adults of both genders.

Keywords: Stress; Natural vestibular stimulation; Self-esteem

Abbreviations: SAM: Sympathetic Adrenomedullary; HPA: Hypothalamic-Pituitary-Adrenocortical; SNK: Student-Newman-Keuls.

\section{Introduction}

Stress has both positive and negative impact. Up to a limited level of threshold, stress may be beneficial.
However, beyond this level, there will be sharp fall in the productivity. According to Rosenberg, "self-esteem is a positive or a negative attitude towards self and high selfesteem indicates the feeling that one is good enough" [1]. Stress adversely affects self-esteem and low self-esteem in turn increases the risk of depression [2]. Hence management of stress is essential for young adults to prevent detrimental effects of stress. Handling of stress 


\section{International Journal of Biochemistry \& Physiology}

varies from person to person and some of the methods include yoga, meditation and listening to music [3]. Optimal stimulation of vestibular system has more soothing effects and is essential throughout the life. Though there are different methods like running, swinging, dancing and jumping to stimulate vestibular system, swinging on a swing is a simple method to stimulate vestibular system $[4,5]$, and it was an ancient practice incorporated in Indian tradition. Vestibular stimulation influence mood states through its connections with cortical areas. Vestibular stimulation may relieve stress by decreasing the levels of cortisol through inhibition of hypothalamic-pituitary-adrenocortical (HPA) axis and sympathetic adrenomedullary (SAM) axis [6]. Anxiety and depression are more common in patients with vestibular disorders [7]. The present study was designed to evaluate the effect of vestibular stimulation on self-esteem in young adults.

\section{Materials and Methods}

\section{Participants}

A total of 300 (130 males and 170 females) young adults were screened. 240 (120 males and 120 females) participants satisfying both inclusion and exclusion criteria were included in the study. A detailed medical history was obtained from all participants and standard physical examination was conducted. Written informed consent was obtained from all the participants included in the study. Selected participants were randomly assigned to four groups by simple random sampling.

Group Con-M ( $\mathrm{n}=60)$ : Control male group (no vestibular stimulation was given)

Group Con-F ( $\mathrm{n}=60$ ): Control female group (no vestibular stimulation was given)

Group Exp-M $(\mathrm{n}=60)$ : Experimental male group (vestibular stimulation was given)

Group Exp-F $(\mathrm{n}=60)$ : Experimental female group (vestibular stimulation was given).

\section{Inclusion and Exclusion Criteria}

Healthy young adults in the age group of 18-24 years who were willing to participate in the study were included in the study. Individuals suffering from any somatic or mental disorders, those with ear infections or any vestibular disturbances, visual disorders, cardiorespiratory disorders were excluded from this study.

\section{Study Design}

This was a longitudinal follow-up study in which, participants were assessed three times. The first assessment was performed during regular classes (with no examination in preceding two weeks and forth coming two weeks), these are pre-intervention values. The second assessment was performed eight months after the intervention (during regular classes), and third assessment was performed sixteen months after the intervention in stressed state (A week before the University examinations).

\section{Study Setting}

The present study was conducted at Little Flower Institute of Medical Sciences and Research and Little Flower Medical Research Centre, Angamaly.

\section{Vestibular Stimulation}

Vestibular stimulation was given by making the participants swing on a swing, according to their comfort (front and back direction) once a day, for 5 days in a week at their leisure timings (8:30-9:30 am, 11:00-12:00 am, 1:00-2:00 pm and 4:00-5:00 pm) in four groups $[8,9]$.

\section{Rosenberg Self-Esteem Scale}

Rosenberg self-esteem scale consists of ten items in which five items assesses positive feelings $(1,3,4,7,10)$ and five items assesses negative feelings $(2,5,6,8,9)$. Participants were asked to respond each item on a fourpoint Like rt scale ranging from $1=$ strongly agree to $4=$ strongly disagree. The scores for the items assessing positive feelings were reversed that is a score of 1 was recorded as 4. Total score is the sum of all item scores. Higher scores indicate higher self-esteem [10].

\section{Ethical Consideration}

The present study was approved by the Institutional Ethics Committee (Angamaly, Kerala, India; No: IEC Jan/10/2014; dated $10^{\text {th }}$ of January 2014).

\section{Statistics}

Data was analyzed by using SigmaPlot 13.0 (Systat software, USA). Median and percentile of all the observations were calculated. Friedman repeated measures analysis of variance on ranks was used to observe the significance of difference in the median values among the groups. Multiple comparison was performed by using student-newman-keuls (SNK) method. Mann-whitney rank sum test was used to observe the significance of difference between the two groups. $p<0.05$ was considered as significant. 


\section{International Journal of Biochemistry \& Physiology}

\section{Results}

The effectiveness of vestibular stimulation in young adults on self-esteem (score) is presented in Figure 1. The median self-esteem score in the control male group was 22. After 8 months, there was no change in the selfesteem score whereas after 16 months, there was a decrease in the self-esteem score. The decrease in the self-esteem score was statistically significant ( $p<$ 0.001 ).The median self-esteem score in the experimental male group was 23 . After 8 months, there was an increase in the self-esteem score whereas after 16 months, there was a slight increase in the self-esteem score. The increase in the self-esteem score was statistically significant $(p<0.001)$.The median self-esteem score in the control female group was 23. After 8 months, there was no change in the self-esteem score whereas after 16 months, there was a slight decrease in the self-esteem score which was statistically significant $(p<0.001)$.The median self-esteem score in the experimental female group was 23. After 8 months, there was a slight increase in the self-esteem score whereas after 16 months also, there was a slight increase in the self-esteem score. The increase in the self-esteem score was statistically significant $(p<0.001)$.After 8 months, self-esteem score was significantly increased in the experimental male $(\mathrm{T}=2076 ; p<0.001)$ and female $(\mathrm{T}=2106 ; p<0.001)$ groups when compared to control male and female groups.

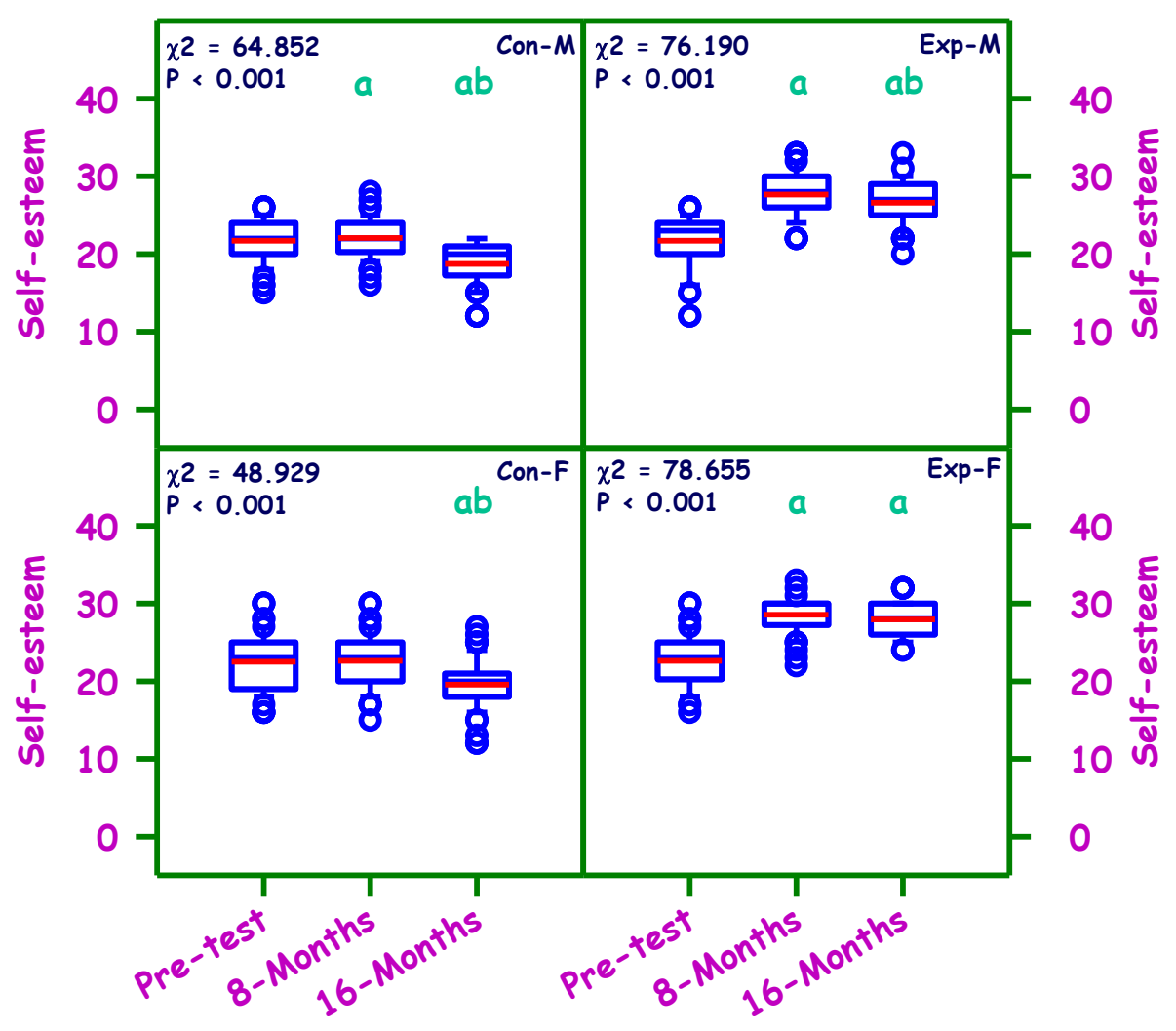

Figure 1: Effectiveness of vestibular stimulation in young adults on self-esteem (score).

Con = Control; Exp = Experimental; $\mathrm{M}=$ Male; $\mathrm{F}=$ Female

The middle blue line is the median and the red line is the mean.

$\mathrm{n}$ - Control $=60$ each; Experimental $=60$ each

The ' $\chi 2$ ' and ' $P$ ' values are by Friedman RM ANOVA on ranks with SNK multiple comparison test.

aSignificantly different from the pre-test group.

bSignificantly different from the 8 months group. 


\section{International Journal of Biochemistry \& Physiology}

\section{Discussion}

Stress is unavoidable and is a major cause for most of the mental illness in modern life including anxiety and loss of self-esteem. Stress in daily life increases negative feelings and eventually leads to depression. Hence, approaches to effectively manage stress are essential to improve quality of life. The correlation of stress and vestibular stimulation is bidirectional, i.e., excessive stress can impair physiology of vestibular system [11] and conversely stimulation of vestibular system is likely to relive stress [12]. Hence the present study tested the hypothesis that longitudinal vestibular stimulation may help in improving self-esteem in relation to stress among female and male student cohort. In this study, self-esteem parameters were measured at baseline and at two different time points post vestibular stimulation. Low selfesteem and higher anxiety levels were reported in patients with vestibular dysfunction. Consistent with observation in this study, balance treatment has showed an improved self-esteem and decreased anxiety in these patients [13]. Vestibular stimulation activates the right inferior frontal region in healthy participants, which reduces the unrealistic optimism [14]. Vestibular stimulation also influences insula, parabrachial nucleus, dorsal raphe nucleus and ensures emotional well-being [15]. Vestibular stimulation provides emotional wellbeing through sensory integration when applied adequately [15]. The present study results are in accordance with these earlier studies as it was observed that there was a significant improvement in the self-esteem followed by vestibular stimulation in both male and female cohorts. Prolonged stress causes deleterious effects on mental health due to dysregulation of HPA axis, including sustained increase in the cortisol levels [16]. High cortisol levels leads to decrease in the length of the dendrites and atrophy of hippocampus, amygdala and prefrontal cortex [17], eventually resulting in dementia [18], depression [19], anxiety [20] and low self-esteem levels [21]. In the present study, it was observed that there was a significant increase in the self-esteem scores following the vestibular stimulation. The study supports adoption of vestibular stimulation as an adjunctive therapy to improve selfesteem.

\section{Conclusion}

The current study provides convincing evidence for the beneficial effects of vestibular stimulation on selfesteem in relation to pre-examination stress among young adults of both genders.

\section{References}

1. Rosenberg M, Pearlin LI (1978) Social Class and SelfEsteem Among Children and Adults. Am J Sociol 84(1): 53-77.

2. Galanakis MJ, Palaiologou A, Patsi G, Velegraki IM, Darviri C (2016) A Literature Review on the Connection between Stress and Self-Esteem. Psychology 7(5): 687-694.

3. Woodyard C (2011) Exploring the therapeutic effects of yoga and its ability to increase quality of life. Int J Yoga 4(2): 49-54.

4. An SJ (2015) The effects of vestibular stimulation on a child with hypotonic cerebral palsy. J Phys Ther Sci 27(4): 1279-1282.

5. Goldberg JM (2012) The vestibular system: a sixth sense. Oxford; New York: Oxford University Press.

6. Winter L, Kruger TH, Laurens J, Engler H, Schedlowski M, et al. (2012) Vestibular Stimulation on a MotionSimulator Impacts on Mood States. Front Psychol 3: 499.

7. Yuan Q, Yu L, Shi D, Ke X, Zhang H (2015) Anxiety and Depression Among Patients with Different Types of Vestibular Peripheral Vertigo. Medicine 94(5): e453.

8. Sailesh KS (2014) Controlled Vestibular Stimulation: A Physiological Method of Stress Relief. J Clin Diagn Res 8(12): BM01-BM02.

9. Kumar Sai Sailesh, Mukkadan JK (2015) Controlled Vestibular Stimulation, Standardization of a Physiological Method to Release Stress in College Students. Indian J Physiol Pharmacol 59(4): 436-444

10. Rosenberg M (1965) Society and the adolescent selfimage. NJ: Princeton University Press.

11. Saman Y, Bamiou D. E, Gleeson M, Dutia MB (2012) Interactions between Stress and Vestibular Compensation -A Review. Front Neurol 3: 116.

12. Kelly BD (2008) Dr William Saunders Hallaran and psychiatric practice in nineteenth-century Ireland. Ir J Med Sci 177(1): 79-84.

13. Bart O, Bar-Haim Y, Weizman E, Levin M, Sadeh A, et al. (2009) Balance treatment ameliorates anxiety and increases self-esteem in children with comorbid 


\section{International Journal of Biochemistry \& Physiology}

anxiety and balance disorder. Res Dev Disabil 30(3): 486-495.

14. McKay R, Tamagni C, Palla A, Krummenacher P, Hegemann SC, et al. (2013) Vestibular stimulation attenuates unrealistic optimism. Cortex 49(8): 22722275 .

15. Rajagopalan A, Jinu K, Sailesh K, Mishra S, Reddy U, et al. (2017) Understanding the links between vestibular and limbic systems regulating emotions. J Nat Sci Biol Med 8(1): 11-15.

16. Alkadhi K (2013) Brain Physiology and Pathophysiology in Mental Stress. ISRN Physiol 2013: 1-23.

17. McEwen BS (2007) Physiology and neurobiology of stress and adaptation: central role of the brain. Physiol Rev 87: 873-904.
18. Lara VP, Caramelli P, Teixeira AL, Barbosa MT, Carmona KC, et al. (2013) High cortisol levels are associated with cognitive impairment no-dementia (CIND) and dementia. Clin Chim Acta 423: 18-22.

19. Cowen PJ (2002) Cortisol, serotonin and depression: all stressed out? Br J Psychiatry 180: 99-100.

20. Lenze EJ, Mantella RC, Shi P, Goate AM, Nowotny P, et al. (2011) Elevated Cortisol in Older Adults with Generalized Anxiety Disorder Is Reduced by Treatment: A Placebo-Controlled Evaluation of Escitalopram. Am J Geriatr Psychiatry 19(5): 482-490.

21. Liu SY, Wrosch C, Miller GE, Pruessner JC (2014) Selfesteem change and diurnal cortisol secretion in older adulthood. Psychoneuroendocrinology 41: 111-120. 